\title{
The entrepreneurship ecosystem: stability and dynamism of social norms in digital transformation
}

\author{
Anna Shkalenko*, and Alexander Konstantinov \\ Volgograd State University, 400062 Volgograd, Russia
}

\begin{abstract}
It was concluded that the need to define the essence of social norms is secondary to the development of the concept of such norms in assessing the stability and dynamism of social norms in the legal and economic doctrine of the business ecosystem. The study of the influence of social norms on the sphere of regulation of economic entities' activity, especially under conditions of technological modernization, suggests that the current Russian economic reality exists in a state of so-called "anomie". It was found that the polyvalent processing of economic transactions in the entrepreneurial ecosystem can work effectively and efficiently at the organizational level but not at the market level. Accordingly, the economic organization as a form and process of relations is the point of reference for the theoretical architecture of relational economics. In this respect, the governance structure must adapt flexibly to social norms and cope with different but interacting polycontextual decision-making logics.
\end{abstract}

\section{Introduction}

The study's relevance lies in the fact that the processes of digitalization, which are currently taking place in the economic and legal environment, have a significant impact on the activities of business entities. Entrepreneurship is subject to the same development trends as the whole sphere of economic activity. However, the specifics of the study of changes in social norms in entrepreneurial activity determine the importance of introducing new institutions that will stimulate the development of the sphere as a whole. At the same time, technological modernization of economic and legal processes is one of the factors determining the development of modern entrepreneurship. However, it should be noted that none of the studies note the innovation factor as the basis for such development and do not highlight the main changes that take place in social norms in the context of digital transformation.

The concept of entrepreneurial ecosystems has attracted considerable attention from scholars, policymakers, and practitioners over the past decade [1-11].

When examining the role of social norms in the digital development of the entrepreneurial ecosystem, it should be noted that there is a low level of regulation of economic digitalization. Despite extensive research and policy interests, the emerging field of entrepreneurial

\footnotetext{
*Corresponding author: oponir@ volsu.ru
} 
ecosystems is still under-theorized and conceptually fragmented. In doctrine and practice, there is an uneven development of the regulatory framework of the sectors, which are inextricably linked to the process of economic development. To date, there are several regulatory problems in the regulation of the economic sphere in the new realities, among which are the following: a large number of barriers set by the legislator that prevent the smooth development of all sectors of the digital economy; uneven digitalization of individual areas entails uneven regulatory regulation; technical and legal problems, which consist in the lack of a unified approach to bringing a set of regulations to the digital realities. All this allows us to speak about the increasing role of social norms in the economy as a whole and the activities of economic entities in the formation of entrepreneurial ecosystems, in particular.

\section{Study methodology}

This study is based on the use of postinstitutional analysis innovative methodology elements based on the interdisciplinary synthesis, which involves overcoming the mono-aspectivity, dichotomous, and dogmatism of many concepts orthodox neo-institutionalism [12]. The choice of this methodology is determined by the fundamentality of this direction, which is the basis of theoretical study. As start-ups have gradually become a critical source of economic growth and an important entry point for regional development in recent years, the ecosystem approach can help bridge the gap between developed and developing economies.

\section{Results of the study}

The process of technological development of economic activities undoubtedly affects the development of social norms of economic entities. The very essence of the digitalization of economic processes development is that there is a need to find new tools to develop the economic environment due to increasing social needs. To address the growing social challenges, organizations must embrace large-scale changes in the innovation process that can create significant business and social impacts.

As a social process, digitalization allows economic actors to generate, collaborate, and create more for the benefit and progress of society through digital communications and applications. The American economist Douglas North [13], studying the concept of the role of economic institutions in society, noted the importance of creating stable structures for the interaction of subjects of society, which aims to reduce uncertainty in such interaction. Such structures consist of social norms (in the context of an alternative to formal norms, i.e., certain customs, values, traditions, etc.) and normative rules, i.e., regulations, contracts, and economic rules.

System-level innovation outcomes in entrepreneurial ecosystems result from specific interaction content, interaction patterns, and resulting building blocks. As discussed in many key articles, the comparison of entrepreneurial ecosystems with traditional clusters and innovation systems is also used to explore unique interaction dynamics [14-15]. First, knowledge serves as a key resource within an entrepreneurial ecosystem where innovation is generated through interdependent interaction. Entrepreneurial ecosystems are a type of cluster in which the overall knowledge base of the cluster does not depend on industry or technology but rather focuses on the overall business process [15]: the launch and expansion of new entrepreneurial ventures. Some common knowledge base characterizes almost all types of clusters. An important element of cluster viability is its ability to facilitate appropriate learning, knowledge sharing, and knowledge spillovers through formal and informal interaction [16]. However, in the types of clusters documented in the received 
literature, this knowledge base tends to be technical, referring either to a given industry (e.g., furniture cluster) or to a given general technology (e.g., biotechnology cluster). Unlike traditional clusters, entrepreneurial ecosystems create unique interactive content in the sense that entrepreneurs gravitate to entrepreneurial ecosystems not to "learn the basics" of a given industry or technology but rather to become more efficient in organizing their activities of enterprises to start and expand [15]. The development of digital technology further helps to lower the threshold for new venture discovery and allows for iterative and experimentationbased heuristics rather than planning-driven business model design [17-18]. This creates a knowledge dynamic in which the entrepreneurial ecosystem facilitates the creation and dissemination of knowledge about organizing efficiently. Entrepreneurs combine this cluster knowledge with their specialized knowledge about a given technology or industry [19]. From the perspective of the digital economy phenomenon [20], it is proposed that entrepreneurs learn about business model experimentation through interactions that contribute to radical business model innovation as system-level outcomes. Despite the relatively narrow definition, their argument emphasizes the technological aspects or "the sociotechnical process of applying digitization techniques to broader social and institutional contexts that make digital technologies infrastructural" [21], making entrepreneurial ecosystems unique.

\section{Discussion of results}

Speaking about the prospects of development of economy digitalization and law and its impact on changes in social norms, it is necessary to note the dual nature of potential deformations of business entities' practices. As mentioned earlier, the entrepreneurial ecosystem is subject to the same development trends as the entire sphere of economic activity in general. The digital transformation of the economy entails a change in the structure of the activities of many business entities. One of the most important consequences of this development, in our view, will be the growing process of replacing the processes previously performed by employees on their jobs with processes that are performed by artificial intelligence. For any national legal system, this means that the law must adapt to new technologies, which raises the question of the extent to which this adaptation affects legal content and legal values [22]. This issue is crucial for the Russian legal context due to contemporary problematic approaches to governance and democracy.

In terms of assessing the transformations in the changes in social norms, political scientists point to the lack of democracy and classify the Russian regime as authoritarian [23]. Linde and Karlsson suggest that authoritarian regimes create e-government in response to the pressures of globalization and to demonstrate modernity and legitimacy to the international community [24].

The design and implementation of an e-justice system inherently entail changing the "institutions", norms and agreements that provide an implicit context for implementing practices. In the process, which J. Lanzara tries to describe by the concept of assembly [25], E-justice systems are built so that they link and modify heterogeneous components that are organizational and normative in nature through technological blocks. The new system results from reusing, replicating, adapting, and combining existing components rather than developing from scratch. In this process, the different uses of technical, organizational, and normative components generate more or less visible shifts in their characteristics and meanings of law and legal values, characteristics and meanings (such as, for example, the very notion of justice) that are often invisible and taken for granted by the community of practitioners who work with them. New entrants such as technology partners and network providers are emerging.

The initial digitalization of economic transactions required fundamental changes to the laws that protect data and ensure the security of emerging digital economies. The transition 
to cryptocurrency and blockchain-based online transactions has brought about major changes in the civil, commercial, and business law governing the market economy not only in Russia but around the world. Economic relationships involving cryptocurrency and blockchain tokens have become more organized and less volatile.

The introduction of the digital rights category and the regulation of smart contracts in the Russian Civil Code have laid the groundwork for further rules on the digital economy. The Russian government has declared the goal of developing this sphere in the Strategy for Development of Small and Medium-Sized Business for 2016. In Section IV, the strategy declares the goal of developing new solutions for alternative sources of financing, including crowdfunding, for high-tech companies. The 2017 Presidential Decree on the Digital Economy required the development of laws governing initial coin offerings (ICOs) by July 2018. An ICO is a fundraising method used by companies primarily offering blockchainrelated products or services. The draft law states the goal to follow the approaches successfully implemented by developed countries (Explanatory note to the draft law on crowdfunding). By October 2019, the law "On attracting investments using investment platforms (crowdfunding)" had passed its third reading in the State Duma and entered into force from 2020. Before this law came into force in Russia, companies acted as crowdfunding platforms [26].

According to Gershovich, "economic value is created by the interaction of actors, especially the asymmetry of information available to the actors concerned, their mimetic behavior and, in a very general sense, their ex post facto behavior" [27]. Consequently, historicity, rather than the assumptions of the rational expectation paradigm concerning individual actors, becomes the core aspect of relational, economic analysis.

With the high adoption of technological development tools, there is a high probability of negative economic consequences, such as high maintenance costs; a reduction in the number of low-skilled workers, and an increase in unemployment, which in turn will reduce the economic and social capacity of states; weak ability to engage local authorities and citizens; non-transparent governance; concerns about privacy, data management, and surveillance coming from both the bottom up and from global experts; concentration of value in the hands of large private players; low resilience to global disruptive events.

On the other hand, there is no doubt that the growing process of technological modernization can positively impact saving the resources of business entities and, accordingly, obtaining higher revenues from economic activities and the social role of entrepreneurship.

According to Whitehead's philosophy $(1929 ; 1941 ; 1967 ; 1968)$, an event society is polyvalent when it uses multilingual games and system references to describe economic issues and uses solutions to establish its relationships with each other. In economics, these relational transactions necessarily take the form of relational contracts, and the appropriate forms of governance used for them must be adapted accordingly.

The process of polyvalent processing of economic transactions can work effectively and efficiently at the organizational level but not at the market level. Accordingly, the economic organization as a form and process of relations is the point of reference for the theoretical architecture of relational economics. In this respect, the term "attitude" is not limited to the interpersonal, social, and trust-based side of dyadic and discrete economic behavior; rather, attitude in relational economics refers to the successful integration of a set of rationalities into an adaptive control structure for the dynamic processing and development of specific economic transactions. In this respect, the governance structure must adapt flexibly to social norms and cope with different but interacting polycontextual decision-making logics. They refer, for example, to the logic of economic, legal, and moral rationality, which, as Latour [28] said, can only process the rationality of rational logic as an interrelated relation. In this world, values - which also, but not exclusively, include moral values - are not stable entities 
that actors can use as endpoints of orientation for their decisions; rather, they are dynamic events, as defined in Whitehead's process philosophy, that must be more concrete ("conformity") and conceptually reflected ("grasping"), and that require adaptive micromechanisms of governance to be operationalized [29].

\section{Conclusions}

The study of stability and dynamism of social norms under conditions of digital transformation identified the consequences of digital modernization of society, manifested in the development of interaction of economic entities within the ecosystem of entrepreneurship.

As a part of relations between society and the state, entrepreneurial activity is controlled and regulated by law. Thus, based on the analysis of the legislation regulating business activities, we can conclude that the legislator imposes certain obligations on business entities, which indirectly affect the social aspect. However, at the same time, the solution of social problems and tasks is not directly related to the sphere of entrepreneurship, referring the resolution of these issues to the competence of public authorities and local self-government. At the same time, the state's role in this matter is to develop a set of soft measures to maintain a high level of social activity of economic entities. At the same time, there are several problems associated with the lack of state legal and economic incentives to encourage entrepreneurship to participate more actively in public social projects. Social norms, being the "rule of dormitory", can create certain behavioral patterns, which will guide the subject in its activities. "A person tends to adhere to stable sets of behavior accepted in a given community, that is, to follow the social norm. At the same time, his actions may be aimed at avoiding (saving) efforts or escaping punishment, as well as at achieving social recognition or joining a certain social group. It is also important that the norms are not a set of purely external restrictions for an economic entity. They are successfully assimilated and become intrinsic to his personal motivations." From the above, it becomes obvious that attempts to build a normative regulation of a new, digital stage of economic behavior and separately the activities of economic entities based solely on legal norms, outside of any ideology or value system, are inevitably subject to the dynamism of the methods of regulating the economic behavior of entities traditionally established in culture. Digitalization is also impacting the entrepreneurial ecosystem by catalyzing the emergence of new types of planning-oriented business models. This creates a dynamism of change in social norms and patterns of behavior of economic actors, in which the entrepreneurial ecosystem contributes to the creation and dissemination of knowledge on how to organize their business by optimizing available resources effectively.

The study of the influence of social norms on the sphere of regulation of economic entities' activity, especially under conditions of technological modernization, suggests that the current Russian economic reality exists in a state of so-called "anomie". Concerning the Russian economic reality, anomie is manifested because all the social values and attitudes accumulated by the older generations are diametrically opposed in their essence to the new, economic liberal system that has replaced the Soviet one. The new stage of economic development is the stage of its digitalization. The rather abrupt and rapid change of economic paradigm towards informatization allows us to conclude a rather high probability of a new round of anomie development in the sphere of business entities' activity.

It is noted that in "stable" systems, in the absence of anomie, each subject of social relations that enters into such relations finds itself in a situation where the rules of social life (i.e., social norms) are already formed, defined so much that they force such a subject to obey. 
In a situation of anomie regulation of economic activity, economic behavior is regulated neither by social and moral values and attitudes nor even by law to the full extent. Normative regulation of economic activity is characterized by a huge number of acts and norms, which often do not have a proper impact on the subjects of such regulation.

In studying the transformation of social norms in the activities of economic entities under the conditions of technological modernization and digitalization of the economy, several important conclusions were made.

First, in the existing legal reality, there is a rather low level of normative regulation of digitalization processes and, accordingly, social norms as a kind of rules of conduct, which have signs of volition and aiming at a socially significant result, which separate it from other types of norms do not have a formed concept.

Second, the role of social norms increases, which, being the "rule of life", can create certain behavioral patterns, which, in turn, will guide the subject in its activities. It was found that the polyvalent processing of economic transactions in the entrepreneurial ecosystem can work effectively and efficiently at the organizational level but not at the market level. Accordingly, the economic organization as a form and process of relations is the point of reference for the theoretical architecture of relational economics.

Thirdly, in the current situation of anomie in the regulation of economic activity, economic behavior is regulated neither by social and moral values and attitudes nor even by law to the full extent. In this respect, the governance structure of business entities in the entrepreneurial ecosystem must be able to adapt flexibly to social norms and cope with different but interacting polycontextual decision-making logics.

The article was prepared with the financial support of the Russian Science Foundation under the science project No. 18-78-10075.

\section{References}

1. Z. J. Acs, E. Autio, L. Szerb, Research Policy 43(3), 476 (2014) doi.org/10.1016/j.respol.2013.08.016.

2. Z. J. Acs, E. Stam, D. B. Audretsch, A. O'Connor, Small Business Economics 1 (2017) doi.org/10.1007/s11187-017-9864-8.

3. J. Alvedalen, R. Boschma, European Planning Studies 25(6), 887 (2017) doi.org/10.1080/09654313.2017.1299694

4. D. B. Audretsch, M. Belitski, Journal of Technology Transfer 1 (2016) doi.org/10.1007/s10961-016-9473-8

5. P. E. Auerswald, Enabling entrepreneurial ecosystems. The Oxford handbook of local competitiveness, 54 (2015)

6. E. Autio, J. Levie, Management of entrepreneurial ecosystems. The Wiley handbook of entrepreneurship, 423 (2017)

7. D. Isenberg, The entrepreneurship ecosystem strategy as a new paradigm for economy policy: principles for cultivating entrepreneurship. Babson Entrepreneurship Ecosystem Project (2011)

8. E. Mack, H. Mayer, Urban Studies 53(10), 2118 doi.org/10.1177/0042098015586547.

9. Y. Motoyama, K. Knowlton, Examining the connections within the startup ecosystem. A case study of St. Louis. Working Paper In Ewing Marion Kauffman Foundation (2014)

10. B. Spigel, Int. J. of Innovation and Regional Development 7(2), 141 (2016)

11. E. Stam, European Planning Studies 23(9), $1759 \quad$ (2015). doi.org/10.1080/09654313.2015.1061484

12. D.P. Frolov, Postinstitutsionalizm, 284 (2017) 
13. D. North, Institutions, Institutional Change and Economic Performance 17 (1997)

14. B. Spigel, R. Harrison, Strategic Entrepreneurship Journal 12(1), 151 (2018) doi.org/10.1002/sej.1268

15. F. Stam, B. Spigel, USE Discussion paper series 16(13), 1 (2016)

16. P. Maskell, Industrial and corporate change 10(4), 921 (2001)

17. M. Ewens, R. Nanda, M. Rhodes-Kropf, J. of Financial Economics 128(3), 422 (2018)

18. E. Reis, The lean startup. Crown Business (2011)

19. S. Tallman, M. Jenkins, N. Henry, S. Pinch, Knowledge, clusters, and competitive advantage. Academy of Management Review 29(2), 258 (2004). doi.org/10.5465/amr.2004.12736089

20. E. Autio, Entrepreneurial ecosystems: concepts and policy challenges (2017)

21. D. Tilson, K. Lyytinen, C. Sørensen, Information Systems Research 21(4), 748 (2010)

22. A. Keen, Why We Must Resist the Temptation of Web 2.0. In The Next Digital Decade. Essays on the Future of the Internet, ed. Berin Szoka and Adam Marcus, 51 (2010)

23. T. Ambrosio, Authoritarian Backlash: Russian Resistance to Democratization in the Former Soviet Union. London: Routledge (2016)

24. L. Jonas, M. Karlsson, Int. J. of Public Administration 36(4), 269 (2013)

25. L. Giovan, Building Digital Institutions: ICT and the Rise of Assemblages in Government. In ICT and Innovation in the Public Sector: European Studies in the Making of E-Government, ed. Francesco Contini and Giovan Lanzara, 9 (2009)

26. T.P. Nekrasova, Ye.V. Shumeyko, Nauchno-tekhnicheskiye vedomosti SPbGPU 10(5), 114 (2017)

27. A. Herscovici, Essays on the historicity of capital. Cham: Palgrave Macmillan (2019). doi.org/10.1007/978-3-030-14838-6

28. B. Latour, Existenzweisen: Eine Anthropologie der Modernen. Berlin: Suhrkamp (2014)

29. J. Wieland, Unternehmung und Gesellschaft. Notizen. In FUGO-Forschungsgruppe Unternehmen und gesellschaftliche Organisation (Ed.), Unternehmen der Gesellschaft, 313 (2017) 